\title{
ENTRE A SOCIOLINGUÍSTICA E A SOCIOLOGIA: LABOV E GIDDENS EM DIÁLOGO
}

\author{
Between sociolinguistics and sociology: \\ Labov and Giddens in a dialogue
}

\author{
Cristine Gorski Severo*
}

\begin{abstract}
RESUMO
Este artigo promove um diálogo entre certas noções da abordagem empírica de Labov e a teoria da estruturação de Giddens. A concepção de fato social defendida por Labov em sua concepção de língua é criticada à luz das reflexões de Giddens. Acredita-se que o ponto de aproximação entre os autores reside no papel atribuído aos sujeitos no processo de mudança social/linguística, rompendo com a visão de total passividade e inconsciência dos sujeitos em relação à dinâmica social e da língua.

Palavras-chave: estrutura; mudança linguística; indivíduo.
\end{abstract}

\begin{abstract}
This article proposes an approximation between some notions of Labov's empirical perspective and Giddens' structuration theory. The concept of social fact assumed by Labov in his definition of language is criticized on the basis of Giddens' social theory. We believe that both theories share similarities in terms of the role (in a certain way active) played by the individual in the social/linguistic change, breaking up with the traditional view of individuals that are passive and unconscious with regards to the dynamics society and language.
\end{abstract}

Keywords: structure; language change; individual.

* UFSC. 


\section{INTRODUÇÃo}

Este artigo, ao se localizar na fronteira entre os estudos sociolinguísticos e sociológicos, pretende estabelecer uma aproximação entre aspectos da teoria empírica de Labov e a teoria da estruturação de Giddens. Devido ao caráter sistemático de alguns dos escritos de Giddens e a suas reflexões sobre os aspectos metodológicos, a natureza do objeto de estudo e os procedimentos analíticos na área das ciências sociais, acredito ser pertinente uma comparação entre Labov e aquele autor. Defende-se que um dos pontos fortes de convergência entre os dois teóricos reside no papel atribuído ao sujeito no processo de mudança da língua (Labov) ou de fenômenos sociais gerais (Giddens).

Inicialmente, exponho as ideias de Labov sobre língua, comunidade de fala e os testes de atitude; em seguida, apresento a teoria da estruturação de Giddens; e, por fim, proponho lançar um olhar crítico, a partir de Giddens, para as noções de língua como fato social e de comunidade de fala utilizadas por Labov, apresentando aproximações entre os autores.

Sucintamente, Labov (1927-), considerado "sinônimo de sociolinguística em muitos círculos linguísticos" (FIGUEROA, 1994, p. 69) postulou, em 1966, juntamente com Weinreich e Herzog, os fundamentos empíricos estruturais para o estudo da mudança linguística (no célebre "Empirical foundations for a theory of language change"). Dois fundamentos são considerados por Labov (1982) como centrais: (i) a condição heterogênea da comunidade de fala e (ii) a gramática da comunidade de fala como objeto de descrição linguística. Desde seus trabalhos iniciais, o linguista tem se dedicado à sistematização da variação/mudança linguística, sendo essa variação amplamente motivada por fatores sociais, os quais são controlados na forma de variáveis extralinguísticas; escolaridade, sexo, classe socioeconômica e idade, por exemplo, são algumas de tais variáveis.

Giddens (1938-), considerado atualmente um dos grandes nomes das ciências sociais e políticas, desenvolveu, entre outros temas, e teoria da estruturação que, segundo o autor, pode ser situada

dentro de um movimento de transição geral de todas as tradições de filosofia e teoria social em direção ao abandono da primazia ou do sujeito ou do objeto, o que envolve certos movimentos de mudança na física também. Trata-se de dar relevo à recursividade, às condições de reprodução da vida social que emergem dela mesma, sem qualquer centro real. (GIDDENS, 1992, p. 2) 
A seguir, apresentam-se as concepções labovianas de língua, comunidade de fala e o problema da avaliação. Na sequência, descreve-se a teoria da estruturação de Giddens. A terceira seção propõe uma articulação entre as abordagens considerando pontos de aproximação e de distanciamento entre elas, tomando-se, para tanto, a dimensão social vinculada à atuação dos sujeitos como eixo norteador da discussão.

\section{LABOV E AS NoçõES dE LÍNGUA E DE COMUNIDADE DE FALA}

Para Labov, a língua é definida como um sistema heterogêneo, ${ }^{1}$ sendo essa heterogeneidade tomada como condição de possibilidade dos estudos de variação/mudança linguística e como um fato social, concepção que sofreu influências da teoria de Durkheim. ${ }^{2}$ Os fatos sociais referem-se a formas de agir, de pensar e de sentir que existem fora das consciências individuais e que possuem um poder imperativo e coercitivo (DURKHEIM, 1973). Apesar da exterioridade e do poder coercitivo dos fatos sociais, Durkheim defende a existência do ator social que (i) possui uma certa consciência dos fenômenos sociais e (ii) é agente no funcionamento da sociedade. Assim, a ideia de "coação" presente na noção de fato social de Durkheim não impede que a vida social seja "tanto 'coercitiva' quanto 'espontânea'” (GIDDENS, 1998, p. 157). Labov parece ter absorvido as duas implicações (i e ii) de ator social de Durkheim, o que se evidencia no papel atribuído às avaliações sociais feitas pelos sujeitos em relação aos usos linguísticos. Isso demonstra que os indivíduos não são totalmente assujeitados ao sistema linguístico, o que relativiza a afirmação de Pagotto (2001, p. 69) de que "o sujeito laboviano é completamente assujeitado ao sistema heterogêneo da comunidade, que é, ao mesmo tempo, a fonte de tal sistema e o locus onde reside".

${ }^{1} \mathrm{Na}$ fala de Labov (1972), "uma vez que tenhamos dissolvido a associação entre estrutura e homogeneidade, estaremos livres para desenvolver as ferramentas formais necessárias para lidar com a variação herdada dentro de uma comunidade de fala” (p. 204). As traduções ao longo do texto são de minha responsabilidade.

${ }^{2}$ Segundo Figueroa (1994, p. 76), "sabe-se que Labov é familiarizado com Durkheim, que ele utiliza o termo fato social, que ele aceita a língua como fato social". Ademais, além de Labov, Durkheim também teria influenciado as reflexões de Saussure e de Meillet sobre a língua como "fato social" (ROBINS, 1981; FIRTH, 1969; BAKHTIN, 1988 [1929]). Contudo, Labov, seguindo as trilhas teóricas de Meillet, não compartilha a mesma compreensão de fato social que Saussure. Em relação a isso, dois aspectos definem a singularidade da concepção sociolinguística: (i) a heterogeneidade do sistema linguístico, (ii) a possibilidade de avaliação da língua pelos sujeitos, embora o sistema, naquilo que o define como "social", exista externamente a eles. Neste artigo, não se pretende discutir as diferentes apropriações do conceito de fato social feitas por Saussure e por Meillet, mas, tão somente, apresentar um diálogo entre a dimensão social da sociolinguística laboviana e a teoria sociológica de Giddens. 
Para Labov (1972; 1978), a definição de língua deve levar em conta, necessariamente, o contexto social, o que implica atribuir à língua três funções: referencial, de acomodação ao ouvinte e de identificação do falante. E é enquanto um sistema mutável e heterogêneo que a língua como estrutura -, com seus aspectos fonológicos, morfológicos, sintáticos e, porventura, semânticos, deve ser vista, sem ser desvinculada do contexto de uma dada comunidade de fala. Dessa maneira, o objeto da linguística deve ser "o instrumento de comunicação utilizado pela comunidade de fala" (LABOV, 1972, p. 187), considerando-se, com isso, que "pressões sociais estão continuamente operando sobre a língua” (LABOV, 1972, p. 3).

A noção laboviana de comunidade de fala recobre tanto aspectos sociais quanto linguísticos, sendo o primeiro prioritário para definir a comunidade: trata-se de atitudes/normas (sociais) sobre a língua, que são compartilhadas pelos falantes e que produzirão efeitos sobre as escolhas linguísticas. Citando Labov: a comunidade de fala "é mais bem definida como um grupo que compartilha as mesmas normas em relação à língua" (LABOV, 1972, p. 158). Tais normas são apreendidas pelo pesquisador mediante o valor que os falantes de uma certa comunidade de fala, afetados por apreciações sociais mais amplas, atribuem a elas. Geralmente, são vinculados valores positivos ao grupo de prestígio cuja fala é dominante na escola, no trabalho, em determinados programas da mídia, etc. Nota-se que a uniformidade das normas compartilhadas pelos falantes geralmente ocorre quando a variável linguística carrega marcas sociais evidentes aos falantes. No caso de não haver tais marcas vinculadas às variáveis, as normas compartilhadas correm o risco de não serem tão uniformes; neste caso, a delimitação da comunidade de fala não poderia se restringir unicamente aos valores compartilhados pelos falantes, pois há variáveis linguísticas que não são, necessariamente, percebidas e manipuladas por esses falantes.

o nível de consciência que o falante tem sobre determinada variável está associado à classificação dos elementos variantes da língua face à avaliação social a que estão sujeitos. Tal classificação engloba os seguintes tipos: (i) os indicadores, que operam num nível inconsciente, dizem respeito aos elementos linguísticos sobre os quais haveria pouca força de avaliação, podendo haver diferenciação social de uso desses elementos correlacionado à idade, à região ou ao grupo social, mas não quanto a motivações estilísticas; (ii) os marcadores, que também permanecem abaixo do nível de consciência, correlacionam-se às estratificações sociais e estilísticas e podem ser diagnosticados em testes subjetivos; (iii) os estereótipos, que são formas socialmente marcadas e reconhecidas pelos falantes. Alguns estereótipos podem ser estigmatizados socialmente, o que pode conduzir à mudança linguística rápida e à extinção da forma estigmatizada. Outros estereótipos 
podem ter um prestígio que varia de grupos para grupos, podendo oscilar entre valores positivos e negativos. (LABOV, 1972; 2001)

As normas compartilhadas pelos falantes e a determinação da comunidade de fala, se tomarmos o modelo classificatório exposto acima, associam-se aos estereótipos e aos marcadores, que podem ser percebidos pelos falantes e detectados por técnicas metodológicas (testes de atitude) que visam identificar a avaliação subjetiva da língua. Já os indicadores ficariam num nível inconsciente e não seriam identificados pelos falantes.

A avaliação da mudança linguística e o seu efeito sobre o processo de mudança dizem respeito ao "problema da avaliação" ${ }^{3}$ - tido como um dos cinco problemas ${ }^{4}$ que envolvem os estudos de mudança linguística, conforme postulado por Weinreich, Labov e Herzog (1968), doravante WLH. Trata-se de um papel central conferido à avaliação social das formas em processo de variação/mudança, sejam elas de prestígio ou não. Ressalte-se que a avaliação subjetiva envolve tanto atitudes conscientes quanto inconscientes em relação à língua.

Apesar da pertinência da dimensão social subjetiva para os estudos da variação, Labov (1972, p. 249) questiona os testes de atitude na medida em que as respostas que eles podem fornecer à questão das causas da mudança linguística não condizem, necessariamente, com o uso que os falantes fazem das variáveis analisadas. Ademais, "a menos que tenhamos evidência verídica de que as pessoas sejam consistentemente recompensadas ou penalizadas por falarem de formas específicas, as atitudes que levantamos em tais testes devem ser consideradas como um mero reflexo do comportamento de fala, ao invés de forças efetivas na vida social" (LABOV, 2001, p. 196). O sociolinguista aponta que os testes podem ser mais seguros quando medem as atitudes em relação a mudanças "de cima", 5 o que caracteriza as variáveis com traços de marcadores ou de estereótipos. Quando a mudança ocorre "de baixo", as variáveis (indicadores) não apresentam nenhum nível de consciência social.

${ }^{3}$ Sobre a importância do teste de atitudes, Zilles e Faraco (2006/) sugerem que a investigação das atitudes e valores acerca dos fenômenos linguísticos é urgente e necessária para o entendimento da norma culta, de forma a evitar tanto a expansão do normativismo (mídia), como o combate interminável (sem diálogo, por sinal) entre os linguistas e os normativistas, a partir da crença desses de que aqueles seriam avessos a qualquer tipo de padrão e ao seu ensino.

${ }^{4}$ Os demais problemas são: restrição, transição, encaixamento e implementação (WLH, 1968, p. 101).

${ }^{5}$ As mudanças de cima (from above) e de baixo (from below) referem-se aos níveis de consciência social e de posições socioeconômicas. Para Labov (1994, p. 78), "mudanças de cima são introduzidas pela classe social dominante, geralmente com consciência pública completa [...] Mudanças de baixo são mudanças sistemáticas que primeiro surgem no vernáculo, e representam a operação de fatores linguísticos internos [...] elas estão completamente abaixo do nível de consciência social". 
A comunidade de fala tida como locus de estudo da variação/ mudança da língua caracteriza a dimensão macro dos estudos linguísticos de Labov. Contudo, uma outra direção de análise da língua também é considerada: trata-se da análise da língua a partir de um escopo micro, e não macrossocial, que postula que as redes sociais que circunscrevem o indivíduo não são independentes das estruturas social, econômica e política mais amplas. Exemplificando, nos estudos sobre variação e mudança linguística na Filadélfia, publicados em Principles of Linguistic Change (2001), Labov salienta a metodologia utilizada: realização de várias entrevistas individuais, participação do pesquisador na esfera social do grupo e questionamentos individuais sobre as redes sociais de relações desses falantes. Segundo o autor, o estudo das redes sociais ofereceria instrumentos de análise social melhores do que o estudo da estrutura social através da profissão, da escolaridade ou dos índices de consumo, uma vez que "estudos de pessoas inseridas em sua rede social nos permitem gravá-las conversando com quem elas geralmente falam - amigos, família e colegas de trabalho" (LABOV, 2001 , p. 326). Como resultado do papel das redes sociais nas pesquisas sobre mudança, Labov comenta que "os efeitos das redes sociais não são os maiores, mas eles adicionam informações essenciais para a descrição da mudança linguística" (LABOV, 2001, p. 341), especialmente sobre os líderes da mudança linguística.

Resumindo, para Labov: (i) a estrutura da língua é passível de ser estudada pela fala dos indivíduos; (ii) tal estrutura é variável; (iii) há uma correlação entre o uso linguístico e a estratificação social; (iv) os indivíduos, em alguma medida, possuem consciência do processo de variação e/ou mudança da língua e são capazes de avaliá-la; (v) tal avaliação exerce influências sobre o processo de variação e/ou mudança da língua; (vi) há forças sociais que atuam nesse processo.

\section{GiddENS E A TEORIA DA ESTRUTURAÇÃo}

A teoria da estruturação de Giddens oferece uma ferramenta de análise das práticas sociais à luz de uma relação estabelecida entre a sociedade, vista como estrutura (regras e recursos) e os indivíduos, entendidos como agentes sociais que assumem identidades nos diferentes contextos sociais. A sociedade não é anterior aos indivíduos, mas estes, ao reproduzirem práticas sociais ao longo do tempo e em diferentes espaços, conservam e produzem uma certa estrutura social; ressalta-se, porém, que os indivíduos não são inconscientes de seus atos - eles os compreendem e são capazes de expressá-los e justificá-los discursivamente. 
Tal teoria se distancia do dualismo existente entre as sociologias interpretativas, que enfatizam o sujeito, e as sociologias estruturalistas e funcionalistas, que priorizam o objeto social. O interesse de estudo de Giddens não é o ator individual e, tampouco, qualquer totalidade social, "mas as práticas sociais ordenadas no espaço e no tempo" (GIDDENS, 1989, p. 2), nas quais indivíduo e sociedade são entendidos "como a dualidade agência e estrutura” (GIDDENS, 1989, p. 133). As atividades humanas, que ocorrem inscritas em um espaço-tempo, não são autênticas, mas recursivas, o que significa que os sujeitos (atores sociais) as recriam constantemente; a recursividade possui um ingrediente puramente humano, que é a reflexividade - para que as práticas continuem, é necessária a reflexividade e, para que esta ocorra, a continuidade deve acontecer. A reflexividade, segundo o autor, deve ser entendida como uma forma de "monitoramento contínuo da ação" que os sujeitos possuem. E por detrás desta perspectiva está a ideia de que os indivíduos são agentes intencionais, que possuem motivos para suas ações e que são capazes, uma vez solicitados, de verbalizar esses motivos.

Giddens postula um modelo de estratificação do agente composto por monitoramento reflexivo, racionalização e motivação da ação. O primeiro implica que os sujeitos monitoram (controlam e regulam) as suas atividades bem como o contexto social e físico onde elas se realizam, e também esperam dos outros o mesmo monitoramento. A racionalização diz respeito ao entendimento que os sujeitos possuem das atividades que desempenham, sendo que "o que os agentes competentes esperam dos outros [...] é que os atores sejam habitualmente capazes de explicar a maior parte do que fazem, se indagados" (GIDDENS, 1989, p. 4-5). Os motivos da ação vinculam-se às necessidades que impulsionam os indivíduos à ação. Enquanto os dois primeiros se associam à continuidade da ação, o último se refere ao potencial para a ação.

Ainda no âmbito do indivíduo, Giddens sugere como componente essencial da vida cotidiana e contemporânea a capacidade de escolha, especialmente em um mundo que oferece uma gama de opções. Isso resulta, entre outros aspectos, no que o autor chama de estilo de vida, ou seja, "um conjunto mais ou menos integrado de práticas que um indivíduo abraça, não só porque essas práticas preenchem necessidades utilitárias, mas porque dão forma material a uma narrativa particular da autoidentidade" (GIDDENS, 2002 , p. 79). Tais práticas geralmente são rotinizadas, existem sob a atuação de determinadas regras e recursos e supõem escolhas que modelam as ações e a personalidade. Exemplificando, o estilo de vida envolve opções sobre hábitos de comer, vestir, lugares frequentados, formas de comportamento no trabalho, pessoas com quem se relacionar, hábitos de leitura, objetos de consumo, preferências de lazer etc. As pessoas tendem a escolher certo 
estilo de acordo com as oportunidades, motivadas pela identificação com algum grupo, pela visibilidade de certos padrões, pela influência da mídia e/ou por aspectos socioeconômicos. O estilo de vida não apenas reflete as diferenças sociais, culturais e econômicas entre os indivíduos e os grupos, mas ele também é responsável pela estratificação e a pluralidade existentes na sociedade. (GIDDENS, 2002).

Um ingrediente importante da vida social é a rotina, que caracteriza não apenas a vida cotidiana como também as formas mais elaboradas de organização social. A rotina, fundada nos hábitos, não significa que os agentes não precisem pensar sobre suas atividades e comportamentos; mas, sim, que "o caráter rotinizado da maior parte da atividade social é algo que tem que ser continuamente "trabalhado" por aqueles que a alimentam em sua conduta no dia-a-dia" (GIDDENS, 2002, p. 69). É no decorrer de atividades diárias que os indivíduos, inseridos em práticas sociais - tidas como "aquilo que as pessoas fazem, i.e., as atividades nas quais elas se engajam ao conduzir a vida social" (MEURER, 2004, p. 88) ${ }^{6}$-, se relacionam em contextos situados de interaçãa ${ }^{7}$. E nesses contextos, que são contextos de copresença, a fala assume papel primordial como veículo discursivo da finalidade comunicativa, sendo que as normas que gerenciam a fala se referem tanto aos aspectos sintáticos e semânticos daquilo que é dito como às situações rotinizadas envolvidas na interlocução.

As propriedades estruturadoras dos sistemas sociais, presentes na produção e reprodução da ação humana, incluem os recursos e as regras. Os recursos, que viabilizam a implementação das regras, dividem-se em alocativos e autoritários, ambos vinculados às práticas sociais; os alocativos referem-se a recursos materiais presentes na produção de poder e existem em função do domínio do homem sobre a natureza. Os autoritários são os recursos não materiais atuantes na produção de poder e existem em função do exercício de uns indivíduos sobre outros. Segundo o autor, a armazenagem desses últimos recursos leva à produção e expansão do poder ao envolver "a retenção e o controle de informação ou conhecimento, de acordo com os quais as relações sociais são perpetuadas ao longo do tempo-espaço" (GIDDENS, 1989, p. 212); isso ocorre através de manuscritos, livros, filmes, cartas, mídia, etc.

${ }^{6}$ As práticas sociais envolvem o uso de regras e recursos por indivíduos localizados em determinadas posições sociais, as quais são constituídas de prescrições sociais (obrigações, prerrogativas, direitos e deveres). (MEURER, 2004).

${ }^{7}$ Os contextos de interação englobam: "a) as fronteiras espaços-temporais [...], a copresença de atores, possibilitando a visibilidade de uma diversidade de expressões faciais, gestos corporais, linguagem e outros veículos de comunicação; c) a percepção consciente e o uso desses fenômenos reflexivamente para influenciar ou controlar o fluxo de interação" (GIDDENS, 1989, p. 230). 
As regras, apesar de atuarem sobre a rotina, não se identificam com ela; elas podem ser rígidas ou flexíveis e referem-se a "técnicas ou procedimentos generalizáveis aplicados no desempenho/reprodução de práticas sociais" (GIDDENS, 1989, p. 17). As regras são aplicadas pelos atores sociais para resolverem seus problemas rotineiros na vida social e, com isso, estruturam a vida cotidiana. A esse respeito, o teórico cita os estudos de Garfinkel que "indicam que as prescrições envolvidas na estruturação da interação diária são muito mais fixas e restritivas do que possam parecer, dada a desenvoltura com que são ordinariamente obedecidas" (GIDDENS, 1989, p. 18). Sucintamente, as regras são divididas em elementos normativos e códigos de significação. Os primeiros ditam as normas, as rotinas e/ou sanções referentes à conduta dos indivíduos e geralmente existem de forma não explicitada, na mente dos sujeitos; os segundos dizem respeito ao fator semântico ou à forma de percepção de mundo dos indivíduos. Tais regras, por fim, visam direcionar os atos e comportamentos dos indivíduos, produzindo um efeito de reprodução (ou mudança) da estrutura social (GIDDENS, 1989; MEURER, 2004). Posto isso, fazer uma análise da estruturação dos sistemas sociais "significa estudar os modos como tais sistemas, fundamentados nas atividades cognoscitivas de atores localizados que se apoiam em regras e recursos na diversidade de contextos de ação, são produzidos e reproduzidos em interação" (GIDDENS, 1989, p. 20).

Nesta perspectiva, as estruturas são vistas como "conjuntos de regras que ajudam a constituir e regular as atividades, definindo-as como de uma certa espécie e sujeitas a uma determinada gama de sanções" (GIDDENS, 1989, p. 70). Salienta-se que a estrutura social não é exterior aos indivíduos, sendo que o conhecimento que os agentes possuem das convenções sociais, de si mesmos e dos outros é inerente à padronização da vida social. Contudo, apesar de os indivíduos terem conhecimento do que fazem, as ações produzem consequências que, muitas vezes, passam despercebidas para os agentes.

Ainda no âmbito dos indivíduos, estes ocupam posições sociais concernentes a identidades sociais definidas numa rede de relações sociais. E essas identidades "estão associadas a direitos normativos, obrigações e sanções que, dentro de coletividades específicas, constituem papéis" (GIDDENS, 1989, p. 230). As regras vinculadas às posições sociais relacionam-se à especificação de direitos e obrigações necessários para um indivíduo que possui certa identidade social.

Finalmente, o conceito fundamental da teoria da estruturação é o de dualidade da estrutura, tida como meio e resultado das condutas sociais - os indivíduos tanto reproduzem como modificam as práticas sociais. E as regras e os recursos que caracterizam a estrutura não existem fora da ação, mas são 
inerentes à produção e à reprodução delas mesmas. Ademais, as estruturas existem apenas "nas atividades cognoscíveis de sujeitos humanos situados, os quais as reproduzem como propriedades estruturais de sistemas sociais incrustados em extensões de tempo e espaço" (GIDDENS, 1989, p. 247).

Tendo feita essa breve apresentação da teoria da estruturação de Giddens, ressaltando o papel atribuído aos sujeitos na manutenção e modificação das práticas sociais, passa-se, a seguir, a uma aproximação entre as perspectivas de Labov e Giddens.

\section{LABOv e Giddens}

A noção de fato social adotada por Labov, a reboque de Meillet e de Durkheim, corresponde à definição clássica de que aspectos considerados sociais, como as maneiras de agir, de pensar, de usar a linguagem, etc., atuam sobre os indivíduos de forma coercitiva, impondo a eles padrões gerais. Essa noção é bastante flexibilizada tanto por Giddens, em sua teoria da relação entre agente e estrutura, como por Labov (2001), quando este atribui ao indivíduo, por exemplo, o papel de líder de mudanças linguísticas. Contudo, uma certa dimensão coercitiva é visível nos estudos de caráter macro e quantitativo de Labov (que focam a comunidade de fala), em que os indivíduos e a linguagem são tomados como instâncias diferentes e independentes, que são postas em correlação de maneira abstrata. Tal correlação, em termos gerais, pode ser problematizada, pois:

(i) reduz os sujeitos a categorias amplas e questionáveis como sexo (se feminino ou masculino), idade, classe socioeconômica e escolaridade, sem maiores reflexões sobre a questão da identidade como, por exemplo: que relação haveria entre o processo de formação da identidade de gênero e certos usos linguísticos?;

(ii) embora reconheça o fato de que o sujeito, a partir de um dado horizonte social, avalia as formas linguísticas e monitora o seu discurso, tal avaliação nem sempre é levada em conta quando, por exemplo, o pesquisador ocupa-se de estabelecer um diagnóstico quantitativo (a frequência) do funcionamento das variantes de uma dada variável linguística;

Ainda no âmbito macro de pesquisa, um outro ponto questionável - à luz da teoria de Giddens - nos escritos de Labov diz respeito ao locus de análise. A ideia laboviana de comunidade de fala, centrada no compartilhamento homogêneo de atitudes e valores sobre a língua pelos membros de uma mesma comunidade, pode ser problematizada em face da diversidade e pluralidade próprias do mundo contemporâneo. Considerando a interpene- 
tração de ambientes locais e globais e a gama de escolhas disponíveis aos indivíduos para a construção de seus estilos de vida, suas identidades e suas redes de relacionamentos, parece um tanto abstrato - salvo em comunidades tradicionais e fechadas ao contato com outros grupos ou com a mídia - considerar a homogeneidade de normas e avaliações como um princípio definidor dos limites de uma comunidade de fala, embora se reconheça $o$ valor metodológico desta opção de Labov por priorizar a dimensão valorativa em detrimento do compartilhamento de um mesmo sistema linguístico para se definir a comunidade de fala. Ademais, essa noção apaga as diferenças individuais ao, por exemplo, desconsiderar a existência de uma variedade de redes sociais e de diferentes práticas sociais que ocorrem em diferentes comunidades de prática localizadas nas comunidades de fala.

Comparando os autores quanto à ideia de estrutura, o termo é central tanto nos trabalhos de Labov (língua tida como sistema heterogeneamente ordenado) como nos de Giddens (teoria da estruturação). Em ambos os casos, a variação é inerente ao sistema/estrutura, o que acaba incluindo uma certa concepção de história atuante no processo de mudança. Para Giddens, a estrutura é flexível e passível de modificações, sendo ela formada por regras e recursos que se vinculam às práticas sociais desempenhadas por indivíduos reflexivos inscritos em papéis sociais. A macroabordagem de Labov pautada em comunidades de fala abre pouco espaço, em termos metodológicos, para a consideração da relação entre linguagem e sujeitos (falantes) que ocorre nas variadas práticas sociais. Essa relação só se estabelece efetivamente quando o locus de análise recai sobre um micronível de análise, o que possibilita ao pesquisador, por exemplo, identificar as origens da mudança no nível dos indivíduos. Sobre esse assunto, Labov (1972) postula o seguinte itinerário para a mudança linguística: origem da mudança a partir de um ou dois indivíduos $\rightarrow$ propagação pela comunidade de fala através dos indivíduos $\rightarrow$ regularização da mudança no nível da comunidade.

Um outro ponto de encontro entre Labov e Giddens está no grau de consciência que ambos conferem (sendo Labov menos incisivo nesse aspecto) aos indivíduos e ao conhecimento que eles possuem sobre, por exemplo, o uso da linguagem. Na teoria de Labov esse ponto fica evidenciado nos testes de atitudes que avaliam os valores sociais que os falantes atribuem a certas variáveis linguísticas - os resultados dos testes, por exemplo, serviriam de base para a delimitação da comunidade de fala. Giddens (1989) defende a relação existente entre a estrutura (regras e recursos) e o agente intencional, sendo que este é capaz de monitoramento, de racionalização e de motivação para a ação. O monitoramento e a racionalização também são levados em conta por Labov quando o sociolinguista trata: (i) dos estilos - variáveis estilísticas que dizem respeito ao monitoramento da fala; (ii) da delimitação da comunidade 
de fala, que envolve a capacidade dos indivíduos de verbalizarem os valores sociais que atribuem à linguagem a partir de um entendimento que possuem sobre o seu uso; (iii) associado aos dois itens anteriores, do grau de consciência que os falantes possuem sobre o uso de certas variáveis: tal grau vai desde um nível inconsciente (com pouca força de avaliação) que caracteriza os "indicadores", passando pelos "marcadores" (onde há um grau menor de inconsciência), até os "estereótipos" (que incluem as formas marcadas e conscientemente reconhecidas pelos indivíduos). Contudo, Labov não leva ao extremo o caráter de reflexibilidade (Giddens) dos sujeitos quando, por exemplo, reduz estes a simples informantes (fonte de dados) e a categorias rotuláveis. Ademais, para Giddens o monitoramento reflexivo é constitutivo dos indivíduos, o que significa que geralmente as pessoas monitoram/ controlam seus comportamentos (inclusive os linguísticos) e os dos demais.

Considero importante ressaltar, contudo, que essa dimensão coercitiva da noção de linguagem como fato social não é absoluta nos trabalhos de Labov. Suas pesquisas de micronível, que, por exemplo, tomam como locus de análise as redes sociais dos indivíduos, mostram que a questão da variação/ mudança linguística está diretamente vinculada à vida dos sujeitos, ou seja, ao processo de constituição da identidade deles. Nesse ponto, a história, os relatos de vida, as atitudes, os comportamentos, os laços de relacionamentos dos indivíduos e seus estilos de vida (Giddens) estão diretamente envolvidos no uso da linguagem. Nesse nível pode-se notar a maneira pela qual as mudanças linguísticas (e outras mudanças sociais) são iniciadas nos sujeitos e propagadas através deles. Nessa perspectiva, o processo de constituição da identidade assume um valor prioritário. Tomando como base a noção de práticas sociais (Giddens), pode-se observar que é nos locais sociais de interação que os indivíduos constroem suas identidades e estilos de vida e, em relação a estes, as variantes linguísticas assumem significado social. Alinho-me aos que propõem que é nas práticas sociais locais que o estudo social da variação/mudança linguística deve iniciar, pois é nesse contexto que se evidencia mais claramente a relação entre a estrutura social (na forma de regras sociais e recursos existentes em determinada comunidade), os indivíduos (o processo de formação das identidades) e os usos linguísticos vinculados às práticas sociais desempenhadas pelos sujeitos.

\section{CONSIDERAçõES FINAIS}

Este artigo teve como objetivo iniciar um diálogo teórico entre as perspectivas sociais de Labov e de Giddens. Apesar de falarem de posições diferentes - Labov, um linguista empírico e Giddens, um sociólogo preocupado 
com as questões metodológicas das ciências sociais - é possível perceber uma aproximação entre os dois quanto à ideia de estrutura variável/ mutável, seja a estrutura linguística ou a estrutura social.

Apesar de a noção de fato social, tão cara à sociologia durkheimiana e herdada pela sociolinguística variacionista, implicar a ideia de coerção, para Labov os indivíduos possuem uma certa consciência da língua (e da variação e/ou mudança), sendo capazes de avaliá-la. Daí a consonância dessa perspectiva com a interpretação que Giddens faz da noção de fato social de Durkheim, de que a vida social seria tanto coercitiva quanto espontânea. Tal avaliação influencia o próprio processo de variação e/ou mudança. Esse traço de consciência dos sujeitos em relação aos fenômenos sociais (incluindo a língua) é compartilhado por Giddens ao defender que os sujeitos (atores sociais) são capazes de monitoramento reflexivo de seus atos e dos atos de outros, de racionalização e verbalização das condições sociais e dos motivos de seus atos, e de motivação para a ação. É por isso que os sujeitos são vistos como agentes sociais e agentes de mudança social; além disso, ressalta-se que as ações dos sujeitos não se reduzem a atos motivados pela coerção social, nem tampouco são desvinculadas de um espaço-tempo. As ações, tidas como práticas sociais, por um lado confirmam as estruturas sociais por serem recursivas e, por outro, (re)configuram as estruturas sociais em um determinado lugar e período, promovendo mudança.

A estrutura não existe anteriormente aos indivíduos - ela existe como memória, na cognoscividade dos sujeitos, e nas ações. Dessa forma, tanto para Labov (em certa medida) quanto para Giddens, não é possível um estudo de cunho social que desconsidere aquilo que os indivíduos têm a dizer sobre os fenômenos em estudo. Trata-se, portanto, de atribuir aos sujeitos um papel fundamental no estudo dos fenômenos sociais - incluindo a língua - rompendo com a ideia tradicional de sujeitos passivos e totalmente assujeitados ao sistema/estrutura linguístico.

\section{REFERÊNCIAS}

BAKHTIN, Mikhail. VOLOSHINOV, Valentin Nikolaevich. (1929). Marxismo e Filosofia da Linguagem. Tradução de Michel Lahud e Yara F. Vieira. São Paulo: Hucitec, 1988.

DURKHEIM, Émile. As regras do método sociológico. In: Os Pensadores. 1. ed., v. 33. São Paulo: Abril S.A. Cultural e Industrial, 1973. p. 373-463.

FIGUEROA, Ester. Sociolinguistic metatheory. Oxford: Pergamon Press, 1994.

FIRTH, J. R. Papers in Linguistics 1934-1951. London: Oxford University Press, 1969.

FOUCAULT, Michel. Microfisica do poder. 14. ed. Rio de Janeiro: Graal, 1999.

GIDDENS, Anthony. A constituição da sociedade. São Paulo: Martins Fontes, 1989. 
. Entrevista com Anthony Giddens. Estudos Históricos, Rio de Janeiro, v. 8, n. 16, p. 291-305, 1992.

. Política, sociologia e teoria social. Tradução de Cibele S. Rizek. São Paulo: Editora da Unesp, 1998.

. Modernidade e identidade. Tradução de Plínio Dentzien. Rio de Janeiro: Jorge Zahar Editor, 2002.

LABOV, William. Sociolinguistic Patterns. Pennsylvania: University of Pennsylvania Press, 1972.

. Where does the linguistic variable stop? A response to Beatriz Lavandera. Working $\overline{\text { Papers }}$ in Sociolinguistics, v. 44, p. 4-22, 1978.

. Building on empirical foundations. In: LEHMANN, W. P.; MALKIEL, Y. (Eds.). Perspectives on Historical Linguistics. Amsterdam/Philadelphia: John Benjamins, 1982. p. 17-92.

.Principles of Linguistic Change: Internal Factors. Cambridge: Blackwall Publishers, 1994.

. Principles of Linguistic Change: Social Factors. Cambridge: Blackwall Publishers, 2001.

MEURER, José Luis. Role prescriptions, social practices, and social structures: A sociological basis for the contextualization of analysis in SFG and CDA. In: YOUNG, L.; HARRISON, C. (Eds.). Systemic functional linguistics and critical discourse analysis. Studies in social change. London/ New York: Continuum, 2004. p. 85-99.

PAGOTTO, Emílio G. Variação e(é) Identidade. 454 f. Tese (Doutorado em Letras-Linguística) Instituto de Estudos de Linguagem, Universidade de Campinas, Campinas, 2001.

ROBINS, Robert H. Lingüística Geral. Tradução de Elizabeth Corbetta e outros. 2. ed. Porto Alegre/Rio de Janeiro: Globo, 1981.

WEINREICH, Uriel; LABOV, William; HERZOG, Marvin. Empirical Foundations for a Theory of Language Change. In: LEHMANN, W.; MALKIEL, Y. (Orgs.). Directions for Historical Linguistics. Austin: University of Texas Press, 1968. p. 95-188.

WEINER, Judith; LABOV, William. (1978). Constraints on the agentless passive. Journal of Linguistics, Cambrigde, n. 19, p. 29-58, 1983.

ZILLES, Ana Maria Stahl; FARACO, Carlos Alberto. As tarefas da sociolingüística no Brasil: balanços e perspectivas. In: GORSKI, E.; COELHO, I. L. (Orgs.). Sociolingüística e ensino: contribuições para a formação do professor de língua. Florianópolis: Editora da UFSC, 2006. p. 23-52.

Submetido em: 20/04/2012

Aceito em: 14/01/2013 